\title{
Optimizing Pregnancy for Intergenerational Health Benefits
}

\author{
Zachary M. Ferraro, $\mathrm{PhD}^{1,2}$ \\ ${ }^{1}$ Faculty of Medicine, University of Ottawa \\ 2 Division of Maternal-Fetal Medicine, The Ottawa Hospital - General Campus
}

ABSTRACT

Pregnancy is a critical period of body weight regulation for both mother and baby. Vital energy-sensing processes are established in utero that aid in nutrient storage and metabolic control later in life. Excessive weight gain during pregnancy and a surplus of maternal resources leads to preferential shuttling of nutrients and growth-promoting peptides across the placenta, resulting in fetal overgrowth - a well-established predictor of childhood obesity. Physical activity during pregnancy offers a safe and accessible way in which one can modify these intricate cellular networks across the maternal-placental-fetal interface to prevent dysregulation and optimize fetal birth weight. This commentary highlights the clinical utility of physical activity during pregnancy and provides practical recommendations as a way to ensure the best health and safety of mother, baby, and future generations.

RÉSUMÉ

La grossesse est une période critique de la régulation du poids corporel pour la mère et le bébé. Des processus vitaux de détection d'énergie sont établis in utero qui contribuent au stockage des nutriments et au contrôle métabolique plus tard dans la vie. Une prise de poids excessive pendant la grossesse et un surplus de ressources maternelles conduit à un transfert préférentiel des nutriments et des peptides favorisant la croissance à travers le placenta, entraînant une prolifération fœtale - un prédicteur bien établi de l'obésité infantile. L'activité physique pendant la grossesse offre un moyen sûr et accessible pour modifier ces réseaux cellulaires complexes à travers l'interface materno-placentaire-fœtal afin de prévenir le dérèglement et optimiser le poids de naissance fœtal. Ce commentaire met en évidence l'utilité clinique de l'activité physique pendant la grossesse et fournit des recommandations pratiques pour assurer la meilleure santé et sécurité de la mère, du bébé et des générations futures.

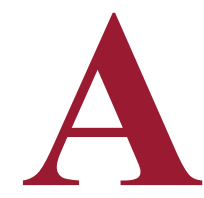

mong the many factors that contribute to childhood obesity (i.e. maternal smoking, nutrition/sugar intake, air pollution, endocrine disruptors, sleep disturbance, lack of breastfeeding), there are two powerful maternal determinants: high maternal body mass index (BMI) and exceeding the Institute of Medicine (IOM) gestational weight gain (GWG) guidelines [1]. Furthermore, pregnancy weight-related issues increase the likelihood of adverse cardiovascular risk factors in offspring [2,3]. Excessive GWG is directly linked to giving birth to a large-for-gestational-age (LGA) neonate [4], which is predictive of downstream obesity and chronic conditions, including Type 2 diabetes and cardiovascular disease [reviewed in 5,6]. Recently, high birth weight and parental overweight/obesity were associated with lower levels of both physical activity (PA) and cardiorespiratory fitness in adolescence [7], further supporting the need for prenatal strategies that optimize fetal growth for long-term health. To the surprise of many, excessive GWG in normal-weight women is associated with higher neonatal fat mass and less favorable body composition (i.e. greater percentage of body fat, less muscle mass)
[8]. This dysregulation in body composition suggests that an energy surplus in utero acts independent of parental genetics with respect to predisposition for excess weight. In fact, according to recent systematic reviews and meta-analyses, excessive GWG increases the risk of childhood overweight/obesity by $30-40 \%[9,10]$, thereby propagating the intergenerational cycle of obesity and the proliferation of chronic disease [5]. This may be due to a host of sociopolitical and physiological factors that promote maternal resource storage, decrements in PA, a loss of metabolic control, and a partitioning of excess energy reserves to the fetus $[5,11]$.

Physical activity remains one of nature's best medicines for prevention and management of chronic disease [12]. However, it is seldom recommended in pregnancy [13]. Furthermore, population PA levels are at an all-time low [14] and reach a nadir during the prenatal period. The reasons for these observations are not well-established, but likely involve a patient-provider knowledge translation discrepancy [15]. Despite the historical dogma and the ensuing clinical recommendations, a pregnant

Keywords: Pregnancy; Physical activity; Pediatrics; Obstetrics; Exercise 
Table 1. Sample exercise presciption for pregnant women without contraindications (adapted from [13,19]).

\begin{tabular}{|c|c|c|}
\hline & Previously Sedentary & Active \\
\hline Program Frequency & $3 \mathrm{~d} / \mathrm{wk}$ & $4 \mathrm{~d} / \mathrm{wk}$ \\
\hline Program Intensity & Low-moderate & Moderate-vigerous \\
\hline Program Duration & $\begin{array}{c}\text { 15min, gradually increase to } \\
\text { 30min sessions }\end{array}$ & $30 \mathrm{~min}$ per session \\
\hline Program Type & $\begin{array}{c}\text { Low impact aerobics (swim, } \\
\text { walk, cycle } \\
\text { Resistance/strength training }\end{array}$ & $\begin{array}{c}\text { Low impact aerobics (swim, } \\
\text { walk, cycle } \\
\text { Resistance/strength training }\end{array}$ \\
\hline
\end{tabular}

* Brief warm-up and cool-down should be incorporated with each bout of activity

†The "talk test" may also confirm that women are not over-exerting

`Avoid exercise in the supine position after approximately 16 weeks’ gestation

women's response to PA is virtually identical to their non-pregnant counterparts and is safe during pregnancy [13]. It is wellestablished that PA has many beneficial physiological effects that lead to health improvements in both mother and baby [16].

In addition to healthy eating, regular PA is a critical mediator of weight gain and a vital component of weight maintenance strategies at all ages. Activity levels during pregnancy are also a predictor of maternal obesity and excessive GWG [17]. Given the importance of PA, the American College of Obstetrics and Gynecology, the Society of Obstetrics and Gynecology Canada/ Canadian Society for Exercise Physiology, and the International Olympic Committee have issued specific guidelines that encourage all pregnant women to engage in routine PA in the absence of contraindications [18-20]. Regular moderate intensity PA during pregnancy has consistently been shown to reduce the incidence of GDM [21-24] and pre-eclampsia [23, 25-29], two pregnancy-related complications implicated in poor neonatal outcomes and downstream child health. Systematic reviews and meta-analyses looking exclusively at PA interventions during pregnancy have shown success in restricting GWG $(-0.36 \mathrm{~kg}$, 95\% Cl: -0.64 to -0.09 kg [30]; $-0.61 \mathrm{~kg}, 95 \% \mathrm{Cl}:-1.17,-0.06$ [31]; $-0.91 \mathrm{~kg}, 95 \% \mathrm{Cl}:-1.76,-0.06$ [32]) but few studies have been designed to examine the effects on longer-term child growth or body composition [33-35]. Data that are available from population-level surveillance, randomized controlled trials, and prospective birth cohorts suggest that regular, moderate amounts of PA can protect against birth weight extremes (i.e. small- and large-for-gestational age), and increase the likelihood of delivering an infant whose birth weight is appropriate for their gestational age [28-36]. Research demonstrating a reduction in fetal growth without an increased incidence of small-forgestational-age infants suggests that sensible prenatal exercise may help normalize nutrient supply to the fetus, thus helping regulate fetal growth [37]. For instance, first and second trimester GWG are directly associated with cord blood hormone levels (e.g., insulin, c-peptide, insulin-like growth factor-I (IGF-I) and IGF-II) at delivery. These growth-promoting hormones are vital for glycemic control and somatic growth and, when in excess, have been implicated in obesity predisposition and metabolic dysregulation [38]. On the other hand, a reduction in growthpromoting peptides has been noted in offspring cord blood of maternal exercisers [39]. This suggests that an active pregnancy may alter nutrient partitioning to the fetus without any demonstrated effect on maternal insulin sensitivity or changes in GWG. Studies by Clapp et al. report that the reduction in birth weight of exercising mothers was entirely accounted for by a reduction of neonatal fat mass with no changes in lean mass compared to the offspring of matched controls [40]. Most striking is the finding that 5 years later the offspring of exercising mothers remained lighter and leaner than their comparators with no difference in other anthropometrics or health outcomes [41]. More recent work has shown that women with a higher total energy expenditure during pregnancy delivered babies with less fat mass, similar lean mass, and thus an improved body composition [42]. A recently published randomized controlled trial concluded that exercise may attenuate adverse pregnancy outcomes including infant size at birth (e.g., macrosomia) when complicated by overweight or obesity [43]. Taken together, PA during pregnancy helps optimize development by preventing overgrowth and inhibiting fetal growth restriction. 
The optimization of infant birth weight in women who engage in regular PA is thought to result from an increased functional capacity of the placenta to appropriately shuttle nutrients across the maternal-placental-fetal interface. This involves mechanisms that increase placental surface area, improve blood flow, and enhance perfusion [44,45]. Evidence from animal and human studies suggests that fetal growth rate is matched with maternal nutrient availability via altered expression of placental transporters, receptors, and signaling pathways involved in nutrient sensing and delivery. This acts to restrict growth when maternal nutrition is limited and accelerates growth in nutrient excess conditions [46-49]. Even though the placenta is a pivotal regulatory organ [50], few groups have explored placental function and cellular mechanisms in pregnancies exposed to maternal exercise [51]. New data suggest that meeting PA guidelines (30 minutes of aerobic activity, 3-4 days/week) during the second trimester is associated with altered expression of genes involved in fatty acid and amino acid transport across the placenta [49,52], which may contribute to altered nutrient delivery to the fetus and subsequent changes in fetal body composition.

Although considerable animal research has illustrated that maternal diet alters developmental pathways and offspring body composition through epigenetic changes in metabolic control genes [52], there is a burgeoning body of literature investigating the effect of maternal PA on these processes. Controlled experiments of maternal PA in animal models has shown beneficial impact on many offspring variables; hippocampal neurons and angiogenesis [53], insulin sensitivity $[54,55]$ and metabolism [56], expression of molecules known to attenuate placental dysfunction [57], high fat diet induced changes in metabolic regulator genes [58], as well as hippocampal neurogenesis, learning, and memory [59]. Thus, it is not unrealistic to presume that PA behaviors, affecting maternal metabolism and the metabolic milieu, could affect fetal body composition and downstream health. As such, PA should be considered alongside dietary factors as keystones to childhood obesity prevention [60].

In summary, it is advisable that trainees and physicians be aware of the tremendous physiological benefits of active living during pregnancy. Every little bit counts and the physiological benefits precede phenotypical change. This is an important talking point to address with patients. With respect to physically active pregnancy, some is better than none, and more is better than some in the absence of contraindications. Patients should listen to their bodies and be open with their physicians about the activities they are involved in and the symptoms that present. For the latter to occur, doctors must engage patients in non-judgmental dialogue and provide encouragement to support patients to live the healthiest life that they can enjoy, while maintaining balance and well-being. After all, small changes during pregnancy have the potential to improve public health on a population level and minimize intergenerational disease risk.

\section{REFERENCES}

1. Institute of Medicine. Weight Gain During Pregnancy: Reexamining the Guidelines. 2009. Washington, DC, The National Academies Press.

2. Fraser A, Tilling $K$, Donald-Wallis $C$, et al. Association of maternal weight gain in pregnancy with offspring obesity and metabolic and vascular traits in childhood. Circulation. 2010;121(23):2557-64.

3. Fraser A, Tilling K, Donald-Wallis C, et al. Associations of gestational weight gain with maternal body mass index, waist circumference, and blood pressure measured 16 y after pregnancy: the Avon Longitudinal Study of Parents and Children (ALSPAC). Am J Clin Nutr. 2011;93(6):1285-92.

4. Ferraro ZM, Barrowman N, Prud'homme D, et al. Excessive gestational weight gain predicts large for gestational age neonates independent of maternal body mass index. J Matern Fetal Neonatal Med. 2011;25(5):538-42.

5. Adamo KB, Ferraro ZM, Brett KE. Can we modify the intrauterine environment to halt the intergenerational cycle of obesity? Int J Environ Res Public Health. 2012;9(4):1263-307.

6. Yu ZB, Han SP, Zhu GZ, et al. Birth weight and subsequent risk of obesity: a systematic review and meta-analysis. Obes Rev. 2011;12(7):525-42.

7. Tikanmäki $M$, Tammelin T, Vääräsmäki $M$, et al. Prenatal determinants of physical activity and cardiorespiratory fitness in adolescence - Northern Finland Birth Cohort 1986 study. BMC Public Health. 2017;17(1):346.

8. Josefson JL, Hoffmann JA, Metzger BE. Excessive weight gain in women with a normal pre-pregnancy $\mathrm{BMI}$ is associated with increased neonatal adiposity. Pediatr Obes. 2013;8(2):e33-6.

9. Mamun AA, Mannan M, Doi SA. Gestational weight gain in relation to offspring obesity over the life course: a systematic review and bias-adjusted meta-analysis. Obes Rev. 2014;15(4):338-47.

10. Nehring I, Lehmann S, von Kries R. Gestational weight gain in accordance to the IOM/NRC criteria and the risk for childhood overweight: a meta-analysis. Pediatr Obes 2013;8(3):218-24.

11. Archer $E$. The childhood obesity epidemic as a result of nongenetic evolution: the maternal resources hypothesis. Mayo Clin Proc. 2015;90(1):77-92.

12. Warburton DE, Nicol CW, Bredin SS. Health benefits of physical activity: the evidence CMAJ. 2006;174(6):801-9.

13. Ferraro ZM, Gaudet L, Adamo KB. The potential impact of physical activity during pregnancy on maternal and neonatal outcomes. Obstet Gynecol Surv. 2012;67(2):99-110.

14. Colley RC, Garriguet D, Janssen I, Craig CL, Clarke J, Tremblay MS. Physical activity of Canadian adults: accelerometer results from the 2007 to 2009 Canadian Health Measures Survey. Health Rep. 2011;22(1):7-14.

15. Adamo KB, Langlois KA, Brett KE, Colley RC. Young children and parental physical activity levels: findings from the Canadian health measures survey. Am J Prev Med. 2012;43(2):168-75.

16. Ferraro ZM, Gruslin A, Adamo KB. An active pregnancy for fetal well-being? The value of active living for most women and their babies. $\mathrm{Br} J$ Sports Med. 2013;47(13):813-4.

17. Olson CM, Strawderman MS. Modifiable behavioral factors in a biopsychosocial model predict inadequate and excessive gestational weight gain. J Am Diet Assoc. 2003;103(1):48-54. 
18. American College of Obstetricians and Gynecologists. Exercise during pregnancy and the postpartum period. ACOG Committee No. 267. Obstet Gynecol. 2002;99:171-3.

19. Davies GA, Wolfe LA, Mottola MF, MacKinnon C. Joint SOGC/CSEP clinical practice guideline: exercise in pregnancy and the postpartum period. Can J Appl Physiol 2003;28(3):330-41.

20. $B \varnothing \mathrm{K}$, Artal $\mathrm{R}$, Barakat $\mathrm{R}$, et al. Exercise and pregnancy in recreational and elite athletes: 2016 evidence summary from the IOC expert group meeting, Lausanne. Part 1-exercise in women planning pregnancy and those who are pregnant. Br J Sports Med. 2016;50:571-89.

21. Artal R, Catanzaro RB, Gavard JA, Mostello DJ, Friganza JC. A lifestyle intervention of weight-gain restriction: diet and exercise in obese women with gestational diabetes mellitus. Appl Physiol Nutr Metab. 2007;32(3):596-601.

22. Dempsey JC, Sorensen TK, Williams MA, et al. Prospective study of gestational diabetes mellitus risk in relation to maternal recreational physical activity before and during pregnancy. Am J Epidemiol. 2004;159(7):663-70.

23. Dempsey JC, Butler CL, Williams MA. No need for a pregnant pause: physical activity may reduce the occurrence of gestational diabetes mellitus and preeclampsia. Exerc Sport Sci Rev. 2005;33(3):141-9.

24. Ong MJ, Guelfi KJ, Hunter T, Wallman KE, Fournier PA, Newnham JP. Supervised home-based exercise may attenuate the decline of glucose tolerance in obese pregnant women. Diabetes Metab. 2009;35(5):418-21.

25. Aune D, Saugstad OD, Henriksen T, Tonstad S. Physical activity and the risk of preeclampsia: a systematic review and meta-analysis. Epidemiology. 2014;25(3):331-43.

26. Osterdal ML, Strom M, Klemmensen AK, et al. Does leisure time physical activity in early pregnancy protect against pre-eclampsia? Prospective cohort in Danish women. BJOG. 2009;116(1):98-107.

27. Saftlas AF, Logsden-Sackett N, Wang W, Woolson R, Bracken MB. Work, leisure-time physical activity, and risk of preeclampsia and gestational hypertension. Am J Epidemiol. 2004;160(8):758-65.

28. Sorensen TK, Williams MA, Lee IM, Dashow EE, Thompson ML, Luthy DA. Recreational physical activity during pregnancy and risk of preeclampsia. Hypertension. 2003:41(6):1273-80.

29. Wolf HT, Owe KM, Juhl M, Hegaard HK. Leisure time physical activity and the risk of pre-eclampsia: a systematic review. Matern Child Health J. 2014;18(4):899-910.

30. Sui Z, Grivell RM, Dodd JM. Antenatal exercise to improve outcomes in overweight or obese women: A systematic review. Acta Obstet Gynecol Scand. 2012;91(5):538-45.

31. Streuling I, Beyerlein A, Rosenfeld E, Hofmann H, Schulz T, von Kries R. Physical activity and gestational weight gain: a meta-analysis of intervention trials. BJOG 2011;118(3):278-84.

32. Choi J, Fukuoka Y, Lee JH. The effects of physical activity and physical activity plus diet interventions on body weight in overweight or obese women who are pregnant or in postpartum: a systematic review and meta-analysis of randomized controlled trials. Prev Med. 2013;56(6):351-64.

33. Adamo KB, Ferraro ZM, Goldfield G, et al. The Maternal Obesity Management (MOM) Trial Protocol: A lifestyle intervention during pregnancy to minimize downstream obesity. Contemp Clin Trials. 2013;35(1):87-96.

34. Dodd JM, McPhee AJ, Turnbull D, et al. The effects of antenatal dietary and lifestyle advice for women who are overweight or obese on neonatal health outcomes: the LIMIT randomised trial. BMC Med. 2014;12(1):163.

35. Seneviratne SN, Parry GK, McCowan LM, et al. Antenatal exercise in overweight and obese women and its effects on offspring and maternal health: design and rationale of the IMPROVE (Improving Maternal and Progeny Obesity Via Exercise) randomised controlled trial. BMC Pregnancy Childbirth. 2014;14:148.

36. Juhl M, Olsen J, Anderson P, Nohr E, Anderson A. Physical exercise during pregnancy and fetal growth measures: a study within the Danish National Birth Cohort. Am J Obstet Gynecol. 2010;202(1):e1-8.

37. Hopkins SA, Cutfield WS. Exercise in pregnancy: weighing up the long-term impact on the next generation. Exerc Sport Sci Rev 2011;39(3):120-7.

38. Rifas-Shiman SL, Fleisch A, Hivert MF, Mantzoros C, Gillman MW, Oken E. First and second trimester gestational weight gains are most strongly associ- ated with cord blood levels of hormones at delivery important for glycemic control and somatic growth. Metabolism. 2017;69:112-9.

39. Hopkins SA, Baldi JC, Cutfield WS, McCowan L, Hofman PL. Exercise training in pregnancy reduces offspring size without changes in maternal insulin sensitivity. J Clin Endocrinol Metab. 2010;95(5):2080-8.

40. Clapp JF 3rd, Capeless E. Neonatal morphometrics after endurance exercise during pregnancy. Am J Obstet Gynecol. 1990;163(6 Pt 1):1805-11.

41. Clapp JF 3rd. Morphometric and neurodevelopmental outcome at age five years of the offspring of women who continued to exercise regularly throughout pregnancy. J Pediatr. 1996;129(6):856-63.

42. Harrod CS, Chasan-Taber L, Reynolds RM, et al. Physical activity in pregnancy and neonatal body composition: the Healthy Start study. Obstet Gynecol. 2014;124(2 Pt 1):257-64.

43. Barakat R, Lucia A, Ruiz JR. Resistance exercise training during pregnancy and newborn's birth size: a randomised controlled trial. Int J Obes (Lond). 2009;33(9):1048-57.

44. Clapp JF 3rd. The effects of maternal exercise on fetal oxygenation and fetoplacental growth. Eur J Obstet Gynecol Reprod Biol. 2003;110 Suppl 1:S80-5.

45. Jackson MR, Gott P, Lye SJ, Ritchie JW, Clapp JF 3rd. The effects of maternal aerobic exercise on human placental development: placental volumetric composition and surface areas. Placenta. 1995;16(2):179-91.

46. Jansson T, Ekstrand Y, Bjorn C, Wennergren M, Powell TL. Alterations in the activity of placental amino acid transporters in pregnancies complicated by diabetes. Diabetes. 2002;51(7):2214-9.

47. Jansson T, Powell TL. IFPA 2005 Award in Placentology Lecture. Human placental transport in altered fetal growth: does the placenta function as a nutrient sensor? -- a review. Placenta. 2006;27 Suppl A:S91-S97.

48. Jansson T, Myatt L, Powell TL. The role of trophoblast nutrient and ion transporters in the development of pregnancy complications and adult disease. Curr Vasc Pharmacol. 2009;7(4):521-33.

49. Brett KE, Ferraro ZM, Yockell-Lelievre J, Gruslin A, Adamo KB. Maternal-fetal nutrient transport in pregnancy pathologies: the role of the placenta. Int J Mol Sci. 2014;15(9):16153-85.

50. Bauer MK, Harding JE, Bassett NS, et al. Fetal growth and placental function. Mol Cell Endocrinol. 1998;140(1-2):115-20.

51. Lewis RM, Greenwood SL, Cleal JK, et al. Maternal muscle mass may influence system A activity in human placenta. Placenta. 2010;31(5):418-22.

52. Brett KE, Ferraro ZM, Holcik M, Adamo KB. Prenatal physical activity and diet composition affect the expression of nutrient transporters and mTOR signaling molecules in the human placenta. Placenta. 2015;36(2):204-12.

53. Akhavan MM, Foroutan T, Safari M, Sadighi-Moghaddam B, Emami-Abarghoie M, Rashidy-Pour A. Prenatal exposure to maternal voluntary exercise during pregnancy provides protection against mild chronic postnatal hypoxia in rat offspring. Pak J Pharm Sci. 2012;25(1):233-8.

54. Carter LG, Lewis KN, Wilkerson, et al. Perinatal exercise improves glucose homeostasis in adult offspring. Am J Physiol Endocrinol Metab. 2012;303(8):E1061-8.

55. Carter LG, Qi NR, De CR, Pearson KJ. Maternal exercise improves insulin sensitivity in mature rat offspring. Med Sci Sports Exerc. 2013;45(5):832-40.

56. Vega CC, Reyes-Castro LA, Bautista CJ, Larrea F, Nathanielsz PW, Zambrano E. Exercise in obese female rats has beneficial effects on maternal and male and female offspring metabolism. Int J Obes (Lond). 2015;39(4):712-9.

57. Gilbert JS, Banek CT, Bauer AJ, Gingery A, Needham K. Exercise training attenuates placental ischemia-induced hypertension and angiogenic imbalance in the rat. Hypertension. 2012;60(6):1545-51

58. Laker RC, Wlodek ME, Wadley GD, Gallo LA, Meikle PJ, McConell GK. Exercise early in life in rats born small does not normalize reductions in skeletal muscle PGC-1alpha in adulthood. Am J Physiol Endocrinol Metab. 2012;302(10):E1221-30.

59. Parnpiansil P, Jutapakdeegul N, Chentanez T, Kotchabhakdi N. Exercise during pregnancy increases hippocampal brain-derived neurotrophic factor mRNA expression and spatial learning in neonatal rat pup. Neurosci Lett. 2003;352(1):45-8.

60. Gillman MW. Early infancy interventions to prevent childhood obesity. Obesity (Silver Spring). 2017;25(5):817-8. 